\section{Original Crommuxnatations.}

ON CERTARN FUNCTIONAL DISEASES OF THE RETINA.

By J. Z. LuUrence, F.R.C.S., M.B.Univ. Lond., Surgeon to the Ophthalmic Hospital, Southwark.

\section{[Concluded from p. 637.]}

I Now come to speak of a very common form of partial paralysis of the retina-a form characterised by its excessively gradual and chronic character. I mean that form which accompanies strabismus.* It had been long known that persons who squinted suffered also from defective vision. But this knowledgo was-and even now is-not so widely diffused as, in the interests of humanity, it should bc. A squint is, even in these days, unfortunately too often regarded as a mere personal deformity, which may, or may not, according to the patient's position or prospects in life, be well left to his own taste and discrotion to be cured or not.

That the exact nature of the paralysis of the retina which accompanies squinting may be completely understood, I may be permitted to make a slight digression, in inquiring whether there exists any predisposing cause that, in the first instance, induces the malady in question? In doing so, I shall limit inyself to the question as it affects the most ordinary form of squint, that of a concomitant convergent one.

It had been long known that there existed a defect of the eye, which consisted in its possessing an unduly high refractive power in proportion to the length of its optic axis, and which constitutes the essence of the optical defect known as short sight, or myopia. But there is a second optical defect of the eye, which, although its existence had been also long known, had always been regarded as quite an exceptional and uncommon form of optical anomaly. We are indebted to the labours of Donders for teaching us that this second anomaly is equally common with myopia, if not more so, and of equal importance. I mean hypermetropia; which I may briefly designate as a deficiency of refractive power in the eye. $\mathbf{M y}$ opia is corrected by a concave lens, hypermetropia by a convex one. Now, it had further been incidentally observed by various authors, that persons who squinted inwards presented a peculiar form of assumed "short-sight", which was remedied, not by concave, but by convex glasses. I myself, some years ago, published a paper on this subject in the Glasgow Miledical Journal, entitled "On the Short-sight of Squinters"; in which I adduced several cases of this to me at that time inexplicable apparent contradiction of facts. But after Donders had recognised the widely spread diffusion of hypermetropia, he further remarked that an overwhelming percentage of cases of ordinary convergent squint was accompanied by this optical defect. Subsequent researches have fully proved the important fact, that hypermetropia is in these cases the cause of the squint; that this latter is a mere symptom in them, and no more a substan. tial disease than are the eruptions of fever or smallpox.

This was a most important step. The way in which hypermetropia induces convergent strabismus

* This subject will be fonnd more fully treated of in the tenth chapter of my work on 2'he Optical Defects of the Eye. may be briefly alluded to. The eje is deficient in refractive power; it would supplement this deficiency if it could. Has it any intrinsic power of doing 80 ? It has; in its power of increasing the converity of the crystalline lens by contraction of the ciliary muscle. Now, in the bealthy eye, this method of increasing the refractive power of the eye is what we all do when we wish to see near objects; it constitutes what is known as the adjusting power of the eye, or its accommodation. This accommodation, however, we only normally exercise when we wish to see a near object; this involves a second muscular act, that of the internal recti muscles-we, in a word, converge the ejes to the near object at the same time that we accommodate their refractive power to it: Thus, convergence and accommodation have, probably from long association, become two almost inseparably connected acts. If we converge the eyes, we instinctively accommodate them; and if we wish to accommodate the eyes, we must at the samo time converge them. Now, the hypermetropic eye, in regarding a near object, must accommodate two-fold: firstly, to supplement its intrinsic deficient refraction; secondly, it has to exercise that normal amount of accommodation that all ejes have to do to overcome the divergence of the rays of light emanating from near objects. It has then, on the whole, to exert an unusual ubnormally large amount of accommodation; this excessive action is often as. sociated with excessive convergence of the eyes. In other words, the eyeballs, in many hypermetropic eyes, to see a close object critically distinct, must converge to a nearer point than that at which the object is actually situated.

Hypermetropic eyes have two choices : imperfect binocular vision or perfect monocular vision. When the latter is attained, one eye necessarily converges so powerfully inwards, as to deviate its optic axis (macula lutea) altogether away from the object which the straight eye is regarding, and, by a power of mental abstraction, ignores the images of any objects formed on its retina. Of course, there remains still a residuary evil-that of a want of binocular vision; this the patient has no further power of correcting. Why most hypermetropic patients prefer imperfect definition to squinting, and what secondary circumstances predispose to the one or the other state, are points which it would lead us too far to discuss in the present paper. The squint is, when it first takes place, not permanent; but occurs only when the patient fixes his eyes intently and attentively on any particular object. I have met with several patients who were perfectly conscious that they did squint under these circumstances. In one very striking instance of a man aged 42, there existed a hypermetropia of $\frac{1}{1}$. This man was always sensible of a strong squint in the one eye, whenever he wished to see an object distinctly. Moreover, what is an additional cogent proof of the dependence of strabismus convergens on hypermetropia, is that natural hypermetropics, who ordinarily exhibit neither a periodic nor a permanent squint, in many instances may be observed to do 80 , if we cover one eye, when they accommodate for a near object; the covered eye then often exhibits a marked inward squint. And what is still more remarkable, a normal eye made artificially hypermotropic by a concave lens exhibits the same phenomenon.

To resume; the squint is then at first periodic, and may at this stage be generally cured without an operation, by convex glasses, prisms, or Javal's stereoscopic method of ocular gymnastics.

In two cases of squint (both in myopic patients, one a con- the second a di-vergent squint), the patients before the operation never could conceive what 
amusement people could finil in looking through a stereoscope: they saw no difference, whether the slides were in or out of the stereoseope. But within a few days these two patients were aqrecably surpriked at then, for the first time in their lives, beingr able to appreciate the benties of the stereosenpe. I now systematically direct all paticnts on whom I hare operated for squint, to commence, as soon as possible, a regular daily course of stereoscopic practice. I prefer ordinary slides to Javal's wafers, as the former, by the amusement they afford, keep the patient up to his work.

I consider this a most important and interestinir supplement to the after-treatment of the operation for squint. Indeed, I would go a step further, and sugrest the stercoscope as a curative measure agrainst squinting in its first (periodic) stare, correcting at the same time any coincilent optical defect. 'That most sagacious olsserver, our eminent Dr. Mackenzie, has suggested (in 1si.4) the stereoseope as an useful exercise in di-vergent sinint. This limitation, I respectfully submit, is unnecessary. For, if $I$ understand the action of Brewster's stereosenpe rigintly, no convergence of the cyes ensues in its use. One prouf of this is, that myopic patients require their reducing concave glasses to see a stereoscopic slide distinctly. One of the above patients required as high a concare as a five-inch ore; I myself require a trn-inch onc. Another proof is direct observation. The eres of persons lookingr through a stereoscope I have always observed to be perfectly central.

'The idea of utilising the stereoscope for the abore purposes, must, doubtless, have occurred to others. I claim no other merit, than that of bringing the method more prominently before the profession.

After the operation for strabismus, the tendency to squint still exists, and may reassert it:self in all its former intensity, if the patient do not, at any rate for all close work, use proper convex glasses.

CASE vir. I operited, by double tenotomy, on a boy aged 11 , for a concomitant convergent squint of the right eye, both eyes being hppermetropic, and having an acuteness of vision (S) of about ?. When I saw him about three woeks after the operation, I found the squint han recurred to the derree of ' 2 "' in the right eye, althnugh I was convinced I had performed the tenotomy completely. I ordered him to wear his 1-16th inch convex neutralisincr glasses. When I again saw him three weeks later, and subsequently upwards of three months afterwards, the squint was quite cured, and had not returned.

In how many such cases a sccond operation has been unnecessurily performed, from the operator's impression that the muscle had not been "completely" divided in the first operation, I am not in a position to say.

After the squint has persisted a considerable lenorth of time, it becomes confirmed. The eye turns in, more or less, always; and from this time forwards its rision gradually diminisices. 'This arises, I believe, from a secondary change occurring in the retina of the squinting eye, which will now form the subject of our further consideration, and which, indeed, has in the first instance induced us to offer the previous rather digressive explanation of the more intimate nature of squinting. Hypermetropia criginates in a congenital smallness of the eye, especially in its antero-posterior axis ; and, in a restricted scnse, may be regarded as an instance of congenital arrest of de. velopment. It is not unnatural under these circumstances to suppose that the retina participates in the general want of formation; and this view is borne out by facts. The acuity of vision is generally somewhat less than normal in all hypcrmetropic eyes (al- together apart from any exceptional co-existence of astigmatism), and is markedly so in all the higher degrees.

The following table contains an analysis of the acuteness of vision in 112 hypermetropic eyos which I have carefully examined diuring the list five years.

Acuity of rision (S) in 112 Hypermetropic Eycs.

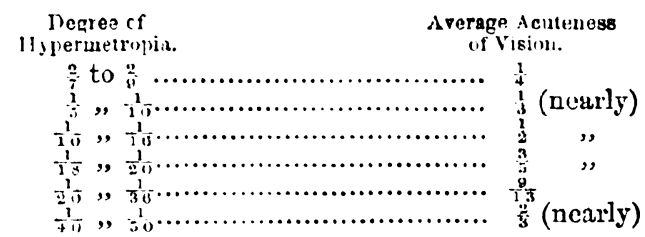

$I$ had formerly been in the habit of using Mannhardt's and Jiiger's types as the tests of the patient's sight. In the above table, I have reduced them to those of Snellen. In every case, with a very few exceptions, the vision has been tested by the patient's power of reading the larger types when he stood exactly twenty (English) feet from them. For this purpose I have employed Nos. 23 to 18 (inclusive).

$A$ person (with his refraction corrected, if necessary) reading :

$$
\begin{aligned}
& \text { No. 1S (Jiger) }=x \text { virn (Snellen) } \ldots 2 \frac{201}{19}
\end{aligned}
$$

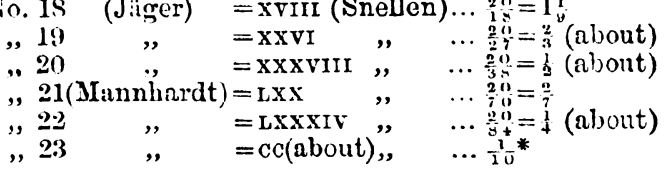

If these equations be not strictly true, still they are perfectly applicable to tho question I wish to $\frac{2}{8}$ solve, which is one of a purely relative nature. $A \stackrel{\mathbb{Q}}{\mathbb{2}}$ glance at the table proves the important fact that $\overrightarrow{\vec{O}}$ the acuity of vision (S) exhilits a progressive diminu- 응 tion as the degree of hypermetropia rises. This 3 would tend to slow, that the imperfect development of the retina proceeds pari passu with that of the eye-? ball generally.

Indeed, in one hypermetropic patient, 1 observed an amblyopia quite equal in amount to that which is, as I shall directly revert to, witnessed in un eye which has squinted for many years.

Case viri. 'Thomas C., an Essex schoolmaster, aged 67 , consulted me in August 1863, on account of lis having observed the sight of the right eye gradually failing bim for the previous six montlis. Heo was so amblyopic with this eye, that with or without glasses be could read no type, however large, if ito were any distance off; but with a 9-inch convexD glass, he was able to read No. 15 (a very large type) at eight inches. With the left, on the contrary, ho read No. 19 as far as twenty feet of with a 30 -inch convex glass; and No. 1 (the most minute type) with N a 9-inch convex glass at eight inches off. Thereo existed then, firstly, a slight degree of hypermetropia; and, secondly, a high degree of presbyopia In addition to the extreme amblyopia of the rightक

* When 1 visited Professor Dondors' clinique at Vtrecht in 1860, T copied, and subsequently hal reprinted in London, a series oD large types, with which, up to the time of Dr. Snellen's introducing
his inproved test-types, I determitued the fur-point in patients. ID had always thouglit these large types were the ones juger introf duced as supplementary to the third edition of his well knwin bove of types. But Dr. Snellen, in a recent communication, informs ne that $\mathrm{N}$ (n) 21, 22, und 23 , if the ones I have for the last five yents been using, are those of Dr. Mannhardt of Hamburg. I have bere to express my obligation to Dr. Suellen in nssising ing in forming the tuble of equivalents to which this note refers. In the calcules tions, I have neglected the fact that s decreases somewhat, esje cially in advanced age. 'This error is of no account, as but few the cases in the table are over forty jears of age.. 
eye, its field of vision was limitod to a circumscribed area around the yellow spot. Now, the interesting fact in this case was, that both fundi oculi appeared identical. In both, the optic papilla was bright at its centre; in both, the choroidal vessels were very clearly reen; in both, the direct image was seen without an eye-piece (hrpermetropic refraction); in neither, were any morbid changes to be detected. In a letter, dated Feb. 1st, 1s(io, he writes me, " $\mathrm{My}$ right "ye is no better; my left as perfect as ever."

Donders has also remarked the diminution of the reuteness of vision in hypermetropic eyes. I La siys "that, even after the correction of the astirmatism of tine hypermetropia, the acuteness of vision usually remains rather considerably below the mormal." (On, the Anomalies of Accommodation and Rejortion of the Lye, p. 255.) Yet, when we come to inspect such eres with the ophthalmoscope, we can detect nothing zoorlid (as we do in all the higher degrees of myopia), if we except the low degree of refractive power of the organ.

The only explanation that I can gire of the amblyopia in these cases is, as I have before said, that tho retina is imperfectly developed-an hypothesis which future anatomical investigation may one day verify ; but which the ophthalmoscope is at present powerless in rerealing. Admitting such a predisposition to imperfect visual perception, we might is priori assume that, in an eye which has not participated in vision for perlaps many years, the perceptive faculty of the retina becomes so blunted, or altogrether practically abolished, as to constitute in it what I venture to designate as a condition of functional paralysis, or as Donders terms it, a "loss of physiological sensibility through psychical exclusion", or inertia.

This assumption is fully borne out by facts. Of thirty-three accurately observed cases of convergent squint, in no fewer than twenty-six was the acuit of vision of the squinting eye less than that of the usually straight eye; the avernge ratio of the one to the other being indeed as low as 1 to 6 . What influenes the are of the patient, the degree and duration of the squint, the degree of the hypermetropia, severally and jointly exert on the acuity of vision, I am not in a position to say. One fact, however, I can vouch for; that is, the utter inadequacy of the ophthalmoscope in explaining this diminution of vision-as in all the cases I have ever examined, I never remember having seen anything further abnormal than a hypermetropic refiaction of the eye.

I think, then, we may fairly admit some such predisposing case, as I have above suggested, to explain the whole.case. For it is a well known fact that, under other circumstances, an eye may be excluded from vision for rears without any paralysis of the retina ensuing. Mr. Soden relates a remarkable case of the kind, in which he removed a cataruet of serenty-six years' standing, and the patient regiained ler sight.**

I have myself operated on a similar case.

CAsE rx. 'Thomas B., a middle aged man, in the employ of an eminent enginecring firm, consulted me last October, on account of the sight of his richt eye having began to fail him for the last two months; so that he could not reconnise a person's features at forty or fifty yards; but I found he could read No. 2e at twenty feet, and that the eye was emmetronie. Focal illumination showed that the impaiment of vision was due to commencing eataract, there being several peripheral opaque strice in the lens. On

* A ereat pat ref the preceliner remarks nu converent strabismas

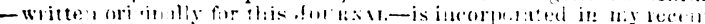
work on the epricial Defe'ts of the Eige. examining his other eye, I found the pupil blocked up by dead white, perfectly opa pue lens-capsule; and, on further inguiry, learnt that he hard been biand of this eye for thirly years, from a thom strikin'r it when beating corer. He would not at first hiral of any operation on the left eye, as he sairl he wats convincel that it was irremediably lost. However, ats he had excellent pereeption of light with this eve, I a last induced him to submit to an operation on it. This consisted in my iemoving nearly all the oparque capsule with cannula-foreeps; but some lois. matter that remaned behind, set up repeated attacks of slight recurent iritis, for which I jerfomed iridectomy. These attarks at last crased; and he regained sufficient vision with the eye to ennble him to recornise objects readily and to read a large-sized type (No. 16).

I have often been asked by practitionors, Do you recommend operatiner early for squint? Certainly, if the squint be confirmed, as early as possible, if the patient is not to lose the sight of the sifuinting eve. Such an unfortunately too common occurence entails two evils. In the first place, the patient loses hinocular vision-not, so small a loss as may be imagined; and, what is more important, should he by any chance lose the sight of his straight eye-a chance to which a one-eyed person is especially liable from his imperfect power of judging of distance-firom an accident, from inflammation, etc., he becomes recluced to a state of altogether irremediable blindness. $A$ case, of another kind however, in which this very nearly happened, actually took place in a patient on whom I operated.

Case $x$. A woman, 4t years of acre, land hat for nine months soft cataract in the right eye; but, as she had the left eye sound to go on with, she never troubled herself about the loss of sight in the other eye. But on May 23rd, 1864, she met with a very curious accident. She was a needle-womian by occupation, and had the habit of carrying her seissors suspended round her waist by a piece of elastic. A dog, seeing the scissors dangling at her side, jumped up in play and snapped at them; he did not succeed in catching them, but they rebounded from his mouth and struck the patient's left eye. On examining the eye, I found a verticul linear wound of the cornea, a wound of the upper part of the iris, the anterior chamber filled with blood, the fundus not illuminable, and vision reduced to mere perception of light. In another ten days, the eveball was so disorganised, that I was compelled to remove it; and sliortly afterwards 1 began to endeavour to procure the aljsorption of the soft cataract in the right eye by repeated punctures, extending over a period of about five months. The ultimate result has, fortunately fur her, turned out most brilliant. When I last testerl her vision, $J_{\text {an. }} 19$ th, 1865 , she was able to rearl No. 1 (Jïgrer) with her reading-glass $(+3)$, and $x \mathrm{x}$ (Sncllen) at fifteen feet with her distance-glass $(+\bar{b})$. I may incidentally mention that, in this case, 1 adopted the expedient of having the two lenses, for realing and distance respectively, set in one (reversible) trimea practical hint worthy of noting in all casses of operated cataracts in which only one cye is used in vision.

I shall, finally, advert to another and distinct functional disease of the eye which has been, very properly I conceive, termed by Dr. Hughlings Jackson "epilepsy of the retina." It is charanterised by transitory loss of vision; the patient partially on wholly loses his sight for a varying period. and then again recovers it in all its previons integrity. 'The ophthalmoscope reveals no morbid conditions of the fundus oculi. In many ciases, the patient has pre.viously suffered from genuine epileptic seizures, 
either amounting to actual fits, or only to an aura epileptica.

The following are two of some instances which I have seen of epilepsy of the retina.

Cask XI. Stephen $\mathbf{P}$., ared 2:, had had two years before I saw him an attack of epilepsy, of which (he said) the effects lasted for three days. On recorering, he found the left eye closed (ptosis), and he could not open it for seven days. From that time, he had had no further fits. He did not remember his sight failing him for any time, or immediately before the fit. What he now complained to me of was, that about once a week or fortnight he would lose his sight for a time, but that he recovered it again. I found that he was amblyopic with the left eye, and appeared to be slightly myopic with both. With the ophthalmoscope, I detected neither a hypermetropic nor a myopic refraction of the cye; the optic discs were reddish, their contours rather ill-defined the ressels were rather small; there was an appearance of tension in the internal tissues.

CASE xir. A man, aged 21, a year ago, whilst at work, found a " mist" come over his eyes sufficiently dense to obscure objects around him. He has ever since been subject to these attacks every four or five weeks. They last for from five minutes to half an hour at a time; the average being a quarter of an hour. During an attack, he can see his way about, and even read with difficult.y. He has never had any fits, but occasionally feels giddy. After one of his attacks, he fecls sickish and has a headache.

I am quite aware how imperfect is the above sketch that I have ventured to offer on thcse obscure functional impairments of the retina. It is necessarily so, from the comparatively slight amount of attention the subject has hitherto commanded. Imperfect as it is, I trust, however, that it may prove sufficiently suggestive to induce others to follow $\mathrm{np}$ what I cannot lelp considering as a most interesting and important study, not only for the op!hthalmologist, lut for all who are interested in the investigation of disease generally.

\section{CARCINOMA OF 'IIIE STOMACH.}

By John Richard Wardell, M.D., M.R.C.P., Physician to the Tunbridge Wells Infirmary.

$$
\text { [Concluded from pagc 63:.] }
$$

of that product; and we must confess that it cannot be entirely divested of any material relations. We know that other diseases, as tuberculosis, gout, insanity, are hereditary; and there is no reason why the cancerous diathesis should not be transmitted in like manner. That constitutional tendency is, however, very greatly promoted or retarded by the opera. tion of external agencies; and there is no doubt that a high state of civilisation conduces to its progress and results. With the exception of the uterus, there is no organ so prone to cancer as the stomach; numerical data in our own and other countries having aloundantly attested this fact. Men are more decidedly prone to it than women, probably on account of their more intemperate habits, greater exposure to vicissitudes of temperature, and greater mental anxicties. Some few instances are given of its occurrence before the age of thirty. It is, however, very seldom observed before the age of thirty-five; far more frequently in those approximating fifty, and in still more advanced life. It belongs to those heterologous changes in the assimilation of the tissues which proclaim declension of vital power, and are intimately associated with age. There is no reason for bclieving that one class is more prone to it, or enjoys a greater immunity from it, than another We meet with it in persons occupying every social position-in the well-nourished, as well as in the halfstarved; in those who live in the country, as well as those who live in cities.

In the great majority of examples, it is primary cancer which affects the stomach. This organ may, it is true, be the seat of the secondary form; but such cases aro mere exceptions to a great general rule. The lymphatic glands may become contaminated by the presence of the disease in neighbouring viscera ; as, for example, when the head of the pancreas, the liver, the spleen, the omentum or mesentery, are affected. Some pathologists have affirmed that it is the colloid variety which is most generally found in the stomach. It would, I think, more cor:rectly express the fact, if we say that it is the scirrhocolloid which is most frequently met with in that particular situation-the hard, fibred basic substance upon which is superimposed the gelatiniform, locular mass. Colloid may and does coexist with the villous, encephaloid, and melanotic forms; but these combinations are not nearly so often observed. The carcinomatous matter is infiltrated into the areolar To attempt to assign any real or regular cause of tissue; because, in such loose and comparatively uncancer, would be at the best but a vain endeavour; and all that we can assert, in the present state of our knowledge, are mere hypotheses and vague surmises, which are either not borne out, or are absolutely refuted, by the facts which accumulated cases present. We know, however, that some occult cause, whatever it may be, effects a very potent change in the fluids ; that it institutes some norbid condition of the blood capable of favouring the genesis of those flagrant cell-growths known as malignant. We see this condition in persons whose bodily conformation and external appearances are most opposite; sometimes in the ruddy and muscular, as well as in the pale and attenuated. The belief of many that it is an hereditary disease is a creed which has long been entertained, and one that is becoming still more preva. lent; for certain it is that, in many instances, other memhers of a family are, upon inquiry, found to have died of the same discase. Nor is the acknowlodgment of this transmission by inheritance at all inconsistent with what we know of the vital properties of the organism. Absolute cancerous material cannot be transmitted with the germ; but some hidden, inscrutable impress is transmissible, which impress at a remote period favours the development

resisting structurc, it there finds less opposition to its deposit. In the course of time, the muscular and other tissues become encroached upon, and cancerous cells are formed within the muscular filamentous sheaths, the molecular constituents of the nuscles being absolutely displaced and occupied by the new formations. One of the great characteristics of carcinoma is displacement and occupation. The product which is substituted not only does not possess the secernent capabilities of the parts removed, but it gravely interferes with the functions of the organ or organs which it has selected as its habitat. Aguin, the vitiated secretions, which are poured out into a hollow viscus, confer additional disorder. Carcinoma of the stomach fully illustrates this evil. The large jelly-like mass, by mixing its perverted exudations with the gastric juice, so injuriously operates upon the normal qualities of that fluid as to render it quite uncqual to the due performance of its office; hence one cause of the sour ejections, the dyspepsia, the occasional attacks of diarrhoea, and that gradual diminution of flesh and strength, which an impaired chyme must inevitably produce. The encephaloid variety grows most rapidly ; the scirrhous most slowly. Scirrhus and colloid may exist in the stomach for 